\title{
INFLUÊNCIA DA QUANTIDADE DE FIBRAS NA DUREZA E RESISTÊNCIA AO IMPACTO DE COMPÓSITOS HIPS/BAGAÇO DE CANA PARA APLICAÇÃO NA INDÚSTRIA DE PET SHOP
}

\author{
Glayce Cassaro Pereira ${ }^{1}$ \\ Gilmara Brandão Pereira ${ }^{2}$ \\ Cirlene Fourquet Bandeira ${ }^{3}$ \\ Sérgio Roberto Montoro ${ }^{4}$
}

Resumo: Nos últimos anos houve um grande avanço tecnológico no desenvolvimento de materiais compósitos reforçados com fibras naturais. Esse aumento do interesse das indústrias e grupos de pesquisa em desenvolver e utilizar materiais feitos a partir de matérias primas renováveis se deu principalmente pelo grande apelo mundial para a utilização de produtos naturais e pela preservação do meio ambiente. $O$ presente trabalho visou a caracterização de compósitos reforçados com bagaço de cana em matriz de poliestireno de alto impacto (HIPS), tendo como objetivo uma possível substituição dos materiais utilizados atualmente na indústria de produtos para pet shop. Foram caracterizadas três famílias de compósitos, nas proporções de 10, 20 e $30 \%$ ( $\mathrm{m} / \mathrm{m})$. Os resultados da dureza Shore A indicaram que a adição da fibra de bagaço ao HIPS não acarretou alterações nos valores da dureza nos compósitos quando comparados ao HIPS puro. E os resultados de resistência ao impacto foi possível constatar que a adição da fibra de bagaço ao HIPS acarretou uma diminuição na resistência ao impacto, quando comparados ao HIPS puro.

Palavras-chave: Compósitos; HIPS; Bagaço de cana; Resistência ao impacto; Dureza Shore A.

\footnotetext{
1 Mestrado Profissional em Materiais/UniFOA, Brasil. E-mail: glaycecp@yahoo.com.br,

2 Mestrado Profissional em Materiais/UniFOA, Brasil. E-mail: brandaoconsultoria.treinamento@gmail.com,

${ }^{3}$ Mestrado Profissional em Materiais/UniFOA, Brasil. E-mail: cirlenefourquet@yahoo.com.br,

${ }^{4}$ Mestrado Profissional em Materiais/UniFOA, Brasil. E-mail: sergio.montoro@foa.org.br.
} 